\title{
RICARDO BASBAUM
}

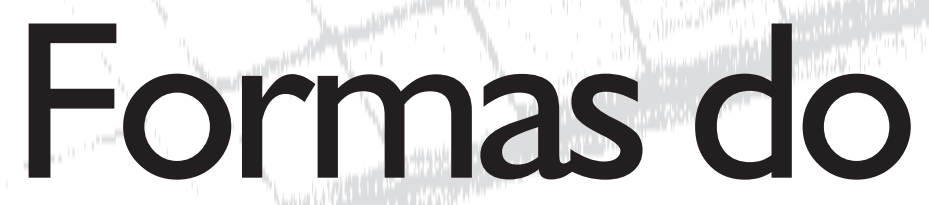

\section{tempo}

"O tempo é o aberto, é o que muda e não cessa de mudar de natureza a cada instante" (Gilles Deleuze, Pourparlers, P. 80). 
Proporei aqui a experiência de perceber algumas das múltiplas formas do tempo, incorporadas em várias pequenas séries de trabalhos de arte. Veremos o trabalho de arte como um dispositivo privilegiado, uma espécie de tecnologia de processamento sensorial, com potencialidade de deflagração do movimento, instaurando as mais diversas qualidades temporais, a partir do encontro com o corpo/mente do espectador (para nós alguém que desfruta de uma proximidade construída por ele(a) em relação àquele(s) trabalho(s)): ao colocar as coisas em movimento é que encontramos o tempo, pois é só aí que podemos estabelecer relações e inter-relações.

Fazendo isso saímos da posição de observadores neutros, testemunhas imparciais e objetivas, e nos colocamos também em ação. Colocar algo em movimento é mover-se, acionar-se, como recurso de lançar-se em combate e captura, estabelecendo ressonâncias e afinidades, mergulhando na corrente que passa, na contracorrente, na correnteza transversal, etc. - experiências do nado disjuntivo.

- memória

- virtualidade e atualização

- processo

- transformação

- metamorfose

- fluxo e fluidez
RICARDO BASBAUM

é artista-plástico,

pesquisador e professor da Universidade Estadual do Rio de Janeiro.

Estão registradas acima algumas palavras, indicando formas de apreensão do tempo, a partir da produção de matéria em movimento. Ou melhor, palavras extraídas da experiência com objetos que se colocam dentro do campo da arte, escolhendo deliberadamente esta área como terreno para o estabelecimento de séries de relações especiais e específicas - "mas não predetermi-

Texto apresentado originalmente no debate "Tempo em Transformação", promovido pela Anpap, em outubro/97. A segunda parte reaproveita trechos de meu artigo "De Fuera Hacia Adentro/De Dentro Hacia Afuera", publicado na revista LAPIZ n. 134-5 (Madri, jul.-set./97, pp. 133-40| 
nadas" -, por colocarem em ação certos mecanismos: "reconhecimento atento", retroalimentação, multissensorialidade, intermídia, heterogeneidade imagem/texto, simultaneidade entre real e ficção, etc. Mas longe aqui de pretender construir uma totalização do campo: falamos de alguns conjuntos possíveis (ou impossíveis), recortes de um eventual território arte (que desde já deve ficar explícita em sua vocação vocabular polissêmica, abrigando sentidos muito diversos, atribuídos conforme as vozes que a anunciam - "estamos falando das mesmas coisas?", não custa nada repetir a advertência).

Vivenciar um trabalho de arte e escrever sobre ele: tarefa cercada da real impossibilidade de representação da experiência, condição que carrega o texto para a região da criação e da invenção, em que a dicotomia reflexão/ficção dá lugar a um tipo de escritura que, por um lado, procura arrancar de sua própria evidência os instrumentos de uma experiência outra, igualmente singular - também insubstituível e intransferível. Nada de pureza crítica ou crua análise técnica; tudo é comentário, conversa, produção de relações, conexões, maquinações que avançam por múltiplos lados, pensamentos em cadeia. Por outro, esta construção textual também investe em uma intrincada trama por dentro da imagem, sabendo-se inseparável da presença do trabalho de arte, enquanto forma heterogênea mas de algum modo complementar: texto e imagem são experiências de modalidades diversas que em algum lugar se encontram de maneira completamente desencontrada; mas ali, cada campo fora de si produz sombras e luzes de uma dinâmica qualquer. Agora sim, há movimento.

Na primeira parte de sua trilogia The Education of the Un-Artist (1971), o (an-) artista americano Allan Kaprow escreve:

Allan Kaprow, "Educaça A-Artista", in Malasartes, no 3 , Rio de Janeiro, abril-maio-ju nho/1976. A trilogia "The Education of the Un-Artist, Parts I, II, III" pode ser encontrada em Allan Kaprow, Essays on the Blurring of Artand Life/University of California Press, 1993). O termo "un-artist" parece se melhor traduzido por un-artista. peça de roupa na caldeira a cada 20 segundos, eu as torno também em um Ambiente Cinético - simplesmente porque pensei nisso e o escrevi aqui. [...] Arte é muito fácil de fazer hoje em dia" (1).

Kaprow aponta essa "facilidade" como um estado paradoxal da "dialética arte/nãoarte", marcado por uma "hiperconsciência [da arte-arte] em relação a si mesma e seu ambiente": "um estado de consciência tão agudo como este permite que o universo inteiro possa ser considerado pelos artistas como uma obra de arte". Importa, para ele, conservar os traços paradoxais desta possibilidade, abandonando a reverência ao circuito institucional da arte. Os artistas do mundo são convidados a abandonar "suas profissões" e tornarem-se "an-artistas" (alguém que "existe apenas por um momento [...] interessado em mudar de atividade, em modernização”). O tipo de atividade que Kaprow procura caracterizar é assim expresso:

"Quando alguém anônimo chamou recentemente nossa atenção para uma pequena transformação que ele ou ela havia realizado na escada de um edifício de apartamentos, e alguém mais nos sugeriu que examinássemos uma parte inalterada da Park Avenue, em Nova York, esses também foram atos de arte. Quem quer que sejam, essas pessoas transmitiram suas mensagens a nós (artistas). Nós fizemos o resto em nossas cabeças" (grifo nosso).

Esta redução da arte a um instante de um jogo mental, professada por Kaprow, decorre, pode-se dizer, de uma possibilidade técnica (daí sua possível banalização) resultante do desenvolvimento da arte moderna e contemporânea deste século, na convergência de, entre outros, Duchamp, vanguarda soviética, e Beuys: através de preocupações com o objeto comum industrializado, com a produção de uma didática deselitizante ou com a transformação de todo mundo em um artista, as operações da arte estenderam-se tanto para um "arrancar-signos-sensoriais-de-tudo" como para 
a atividade complementar de "sobrepor-àscoisas-signos-verbais" - ações realizáveis por todos: o mundo e a vida estão repletos de possibilidades sensoriais e narrativas jamais imaginadas e realizadas pelo campo convencional da arte. Kaprow avança dentro desta possibilidade, elaborando cinco modelos de "arte experimental" de acordo com "tipos básicos encontrados no diaa-dia, nas profissões não-artísticas e na natureza" (2): modelos situacionais (ambientes, costumes e ocorrências comuns, muitas vezes encontrados prontos, readymade); modelos operacionais (como coisas e hábitos funcionam e o que fazem); modelos estruturais (ciclos naturais e ecológicos, formas das coisas, lugares e acontecimentos humanos); modelos auto-referentes ou de feedback (coisas ou eventos que falam ou refletem sobre si próprios); modelos de aprendizagem (investigações filosóficas, rituais de treinamento sensorial, manifestações educativas). Esses modelos ambicionam fornecer possibilidades de compreensão de certos trabalhos de arte antes em suas ligações com o "mundo real" do que em relação ao mundo da arte. Um jogo ou processo que se constrói em "nossas cabeças", escreve Kaprow, como um "fluxo" que substitui a obra de arte, diretamente relacionado à vida.

Devemos perceber o pensamento e as proposições de Allan Kaprow como o desenvolvimento de uma modalidade de temporalização que está na raiz das possibilidades da arte contemporânea. A manobra duchampiana de enquadramento e isolamento de um objeto, deslocando-o de seu contexto original para o mundo da construção de um discurso ou narrativa - recuperado através do campo da arte -, é repotencializada a ponto de incorporar a esfera da natureza e dos rituais e relacionamentos humanos, todos "objetificáveis", transformáveis em um conjunto autônomo conectado a outros conjuntos: surge a possibilidade de este novo conjunto estabelecer séries de relações antes anestesiadas (como propõe Cildo Meireles em suas Inserções em Circuitos Ideológicos) ou invisíveis, mas que agora percorrem o territó- rio da visibilidade e acionam potencialmente outras esferas da vida e do conhecimento. É a partir da possibilidade do estabelecimento destas cadeias de relações múltiplas junto às coisas que reside uma primeira presença do tempo como condição da prática contemporânea da arte, em sua tecnologia de produção de metamorfoses.

Gilles Deleuze, ao criar o conceito de imagem-tempo (3), mostra como o cinema do pós-guerra conduz a imagem "para além do movimento", estabelecendo conexões com o pensamento: faz-se "do movimento a perspectiva do tempo", busca-se os "elementos e relações internos que tendem a substituir o objeto, a suprimi-lo à medida que aparece, deslocando-o sempre" (operações que conduzem à transformação descrita no parágrafo anterior). Este processo de temporalização da imagem só ocorre na história do cinema, para Deleuze, a partir do neo-realismo italiano, quando emergem "situações puramente óticas e sonoras" que estabelecem um "espaço qualquer”, outro, de passagens. São traçados novos tipos de signos sensoriais "puros", que "tornam visíveis e sonoros o tempo e o pensamento": "opsignos" e "sonsignos" "entram em relação com outras forças [...] abrindo-se para as revelações da imagem-tempo, da imagem-legível e da imagem-pensante, [...] remetendo a crono-signos, lekto-signos e noo-signos". Deleuze propõe aqui uma operação de extração de signos sensoriais como parte fundamental da temporalização da imagem e produção de relações mentais, de pensamento. Isso nos interessa enquanto possibilidade de reinterpretar as colocações de Kaprow, em sua concepção de atividades experimentais an-artísticas, uma vez que estas - para Kaprow - estão sempre baseadas em modelos da natureza que reverberam por todos os lugares: “Arte, que copia a sociedade copiando a si própria, nãoé simplesmente o espelho da vida. Ambas são construídas. A natureza é um ecossistema". Pode-se dizer que Kaprow procura extrair sensorialidade pura de eventos quaisquer da natureza e da vida, para deste modo lançar estes eventos em uma cadeia de pensamento que os ultrapassa,

\footnotetext{
2 A. Kaprow, "The Education of the Un-Artist, Part III", p. 130

3 Gilles Deleuze, Cinema 2: A Imagem-Tempo, Brasiliense 1990, pp. 9-36.
} 
Na página

seguinte, João

Modé,

Mergulho no

Reflexo/Ritos

de Passagem,

1996.

Instalação no

Espaço

Cultural Sérgio

Porto, Rio de

Janeiro;

abaixo,

Brígida Baltar,

A Coleta da

Neblina, 1998 contaminando-os com outras esferas de sentido. Estabelece-se uma qualidade diversa de relações, recuperáveis através do campo da arte (ou an-arte) em todas as suas múltiplas interfaces transdisciplinares. Relações que se efetivam na costura de uma narratividade entretecida junto à materialidade dos eventos propostos, realizando a presença de um pensamento verdadeiramente verbivisual, composto pelo binômio matéria-pensamento.

A intensidade de agrupamentos sensoriais permite o reencadeamento das mais diferentes matérias e eventos no fluxo de pensamento da arte contemporânea. Temporalidade instantânea a percorrer sucessivos corpos enquanto mediações, cristalizando-se no artista (EU) ou nos espectadores (VOC $\hat{E})$ e revertendo estas posições (VOCÊ torna-se EU e vice-versa) quando a fruição da obra torna-se possível apenas a partir de um paradigma de invenção/criação: as sucessivas recepções do trabalho constituem novos jogos de relações mentais, novos conjuntos de signos sensoriais agregados à narrativa, nós de um rizoma que redesenha a cada vez a existência da coisa ou evento enquanto possível jogo da arte.

Gostaria agora, sem perder de vista o horizonte delineado até aqui, de tecer alguns comentários a respeito de seis artistas brasileiros (incluindo-me nesta lista), destacando o uso que fazem, em suas obras, de diferentes formas do tempo.

\section{MEAAMORFOSE, TRANSFORMAÇ̃̃OO}

Quando, em fins de 1996, João Modé construiu seu ambiente-labirinto Mergulho no Reflexo/Ritos de Passagem (Espaço Cultural Sérgio Porto, Rio de Janeiro), creio que poucos deram-se conta da importância da montagem proposta, coroamento de uma seqüência de outras duas exposições individuais, realizadas alguns meses antes (4). A partir deste conjunto de obras, Modé opera um deslocamento de foco em seu próprio trabalho, adotando preocupações na direção da conjugação corpo/natureza, sem perder de vista a questão da individuação. Um percurso que combina autoquestionamento, transformação, corpo e identidade. Mergulho no Reflexo/Ritos de Passagem é composto de duas seções, interligadas por um pequeno corredor, sendo tudo articulado através de uma estrutura de madeira. Desse modo, o espaço da galeria é dividido em três áreas, iniciado por uma apresentação de si - onde o artista lança pelo chão cabelos e pêlos de seu próprio corpo-, e concluído em uma sala repleta de terra, contendo plantas e insetos vivos. $\mathrm{O}$ ambiente apresenta, ainda, largas superfícies compostas de casca de cipó, espinhos, casulos e raízes, matérias em si carregadas por um sentido bruto de natureza, ao qual o visitante não fica imune. Aqueles que entram na instalação são conduzidos, de uma área a outra, através do corredor de passagem, onde, momentaneamente, são "abandonados pela obra" (5), até enfim atingirem a segunda sala, mais ampla, em que o percurso é resolvido nos termos de um ambiente fechado, de total imersão. Não se trata aqui de uma mera ilustração da passagem entre cultura e natureza, uma vez que o movimento desta instalação procura avançar sobre tal dicotomia, propondo antes a inexistência de qualquer paraíso primordial, ao apresentar um mundo arrancado a partir de fragmentos de um corpo - o próprio: nada aqui fala de uma proporcionalidade ideal ou de um equilíbrio ser humano/natureza, sob a regência de uma teoria unificadora qualquer a atravessar ambos. As paisagens exteriores não mais importam - se é que existem ainda, ou existiram algum dia - quando a construção objetivamente exteriorizante nos fala de um mundo interno hiperdilatado, recém-chegado ao momento de confrontação quase absoluta com o vazio deserto das próprias paisagens. Trazer insetos, plantar uma árvore, interligar o teto ao chão com raízes: Modé não gesticula por uma ecologia politicamente correta, mas procura - vamos assim dizer-" "plantar-se", "colonizar-se", "fertilizar" as colinas que deslizam por dentro, derivam dos processos da vida e da 


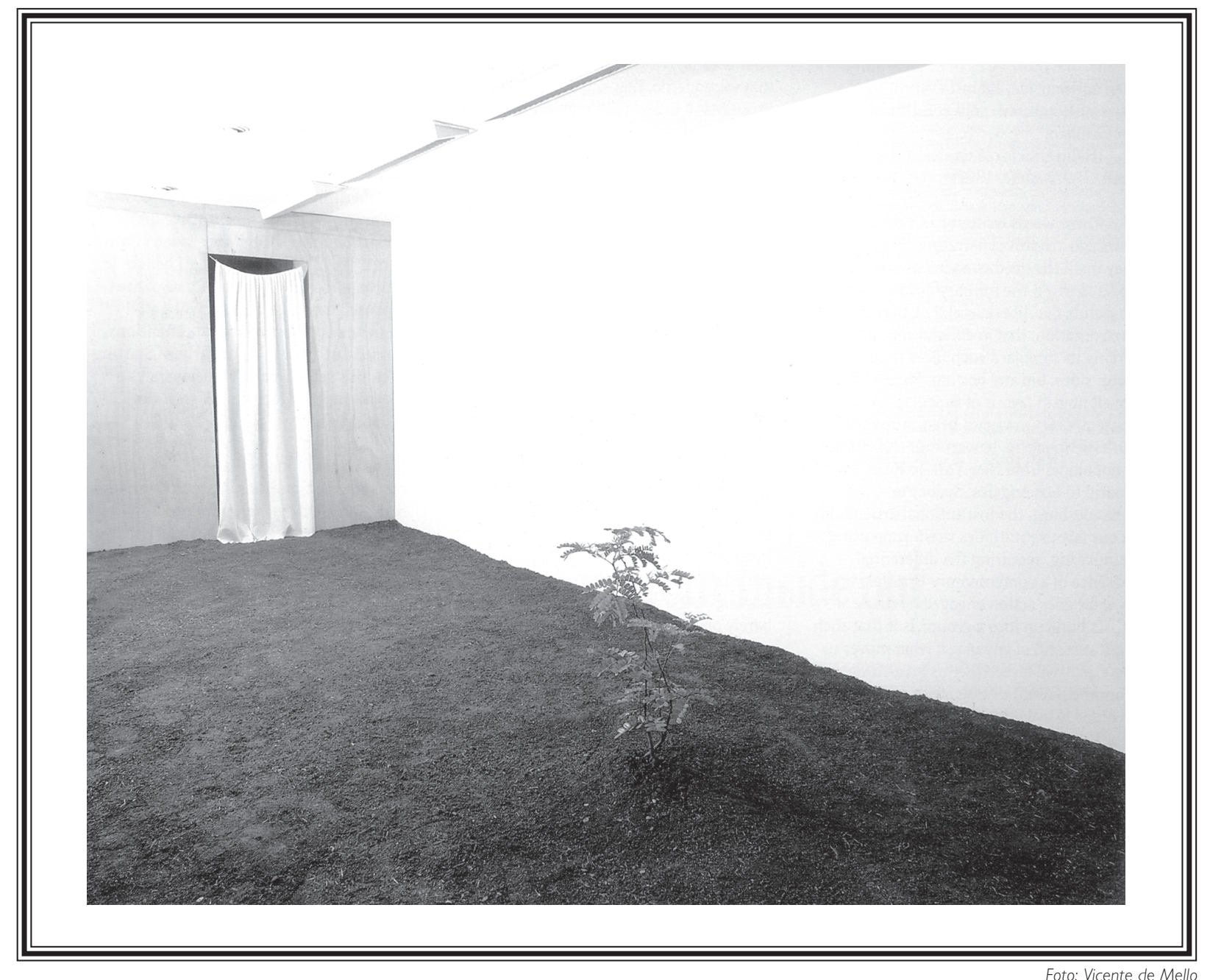

Foto: (colaboração) Juliana Rocha

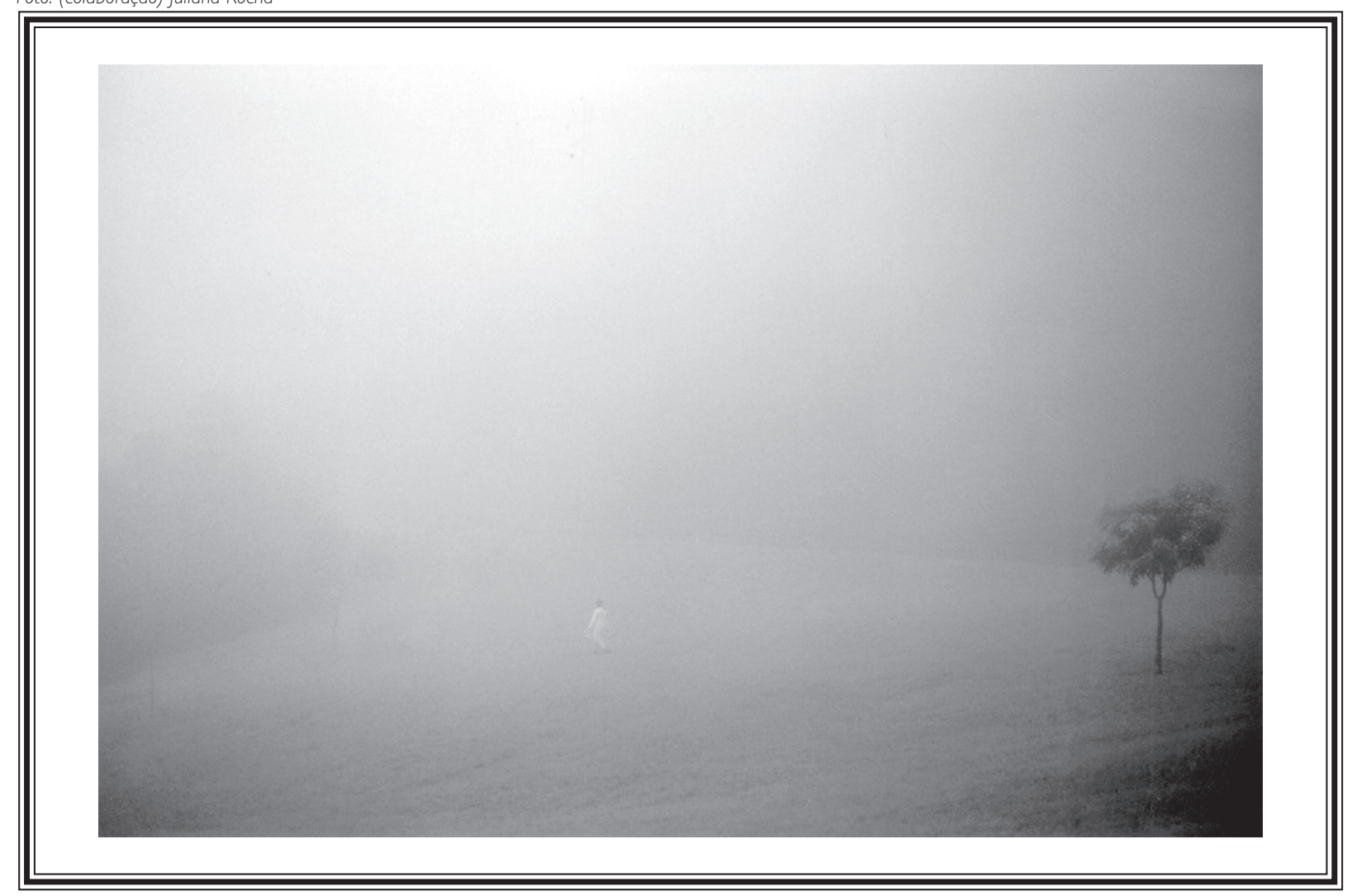


existência. Por isso essas manobras têm obrigatoriamente que se afirmar pelo transpessoal, exibindo o quanto somos pouco de nós mesmos e muito de todo o resto, habitados por coletividades orgânicas, culturais, minerais, etc.

Sem qualquer dúvida, a exploração do "mundo interior" foi uma das fronteiras da era moderna, que multiplicou em todas as direções os confrontos entre o universo individual, privado, e os princípios da esfera pública - afinal a potência individual, irreverente, explosiva, esquizofrênica, iconoclasta, sempre foi o pólo subversivo da modernidade. Somente a segunda metade deste século conheceu os resultados da progressiva "interiorização" da política e da ciência, conduzindo ao que Allen Ginsberg chamou de "Solidão Pública" (6), e à conseqüente expansão multissensorial dos anos 60, que efetivamente resulta da implosão produtiva do desregramento rimbaudiano de todos os sentidos. Tanto Lygia Clark como Hélio Oiticica marcam esta passagem de modo fundamental, ao realizarem obras de caráter intensamente prospectivo, co-fundadoras desta região da interno/exterioridade, colaborando na criação de uma nova forma de espaço caracterizado pela fluência möebiana dofora/dentro: por isso são artistas fundamentais neste final de milênio pós-moderno, quando a crise passa pela difícil administração das superfícies muito amplas de uma interioridade nunca vista assim tão grande... e tão vazia.

\section{EXPANSÃO, MULIPLLCAÇÃO}

Uma operação similar é realizada pela artista Brígida Baltar, no sentido de trabalhar o espaço em torno numa relação direta consigo própria, envolvendo uma incorporação da natureza, seguida, na mesma medida, por uma expansão de si no ambiente. Introjeção e expansão estão especialmente presentes na obra Abrigo (1996), em que Baltar escava o molde de seu corpo na parede de sua casa, revelando o desejo de construir um local dentro do fora, desaparecendo e ao mesmo tempo fundindo-se com o entorno; todo o espaço de moradia transforma-se em uma extensão de seu corpo. A ação de pensar-se no fora, no espaço, nos objetos, avança para além do gesto expressivo, pois não se trata da manifestação de subjetividades ou individualidades sobre a matéria mas sim da configuração objetiva do gesto plástico enquanto passagem, reordenação do mundo das coisas em direção a um repovoamento - a posteriori - interiorizante. Brígida Baltar assimilou a lição de Waltércio Caldas - que poderia ser enunciada como "a clareza ofuscante do objeto de arte produz um efeito de suspensão que remete ao vazio, construindo uma impessoalidade enquanto pura superfície à deriva" - conectando-a àquela de Félix Guattari, de modo a acrescentar um papel de "produtor de subjetividade" (7) ao componente plástico, enfatizando o objeto como “composto heterogêneo", realizando uma experiência de "subjetivação do espaço" e não um gesto expressivo subjetivo qualquer sobre a matéria. O resultado final dos trabalhos revela um interesse pela imagem, sem dúvida a interface multiplicadora com maior poder de sedução, que aqui funciona enquanto registro e produto final, ainda que pouco permeável ao impacto da experiência: a objetiva assume a opção de mostrar com clareza, para que não haja dúvida na reconstrução documental da cena - como em Coleta de Neblina (1997), onde os elementos são exibidos em toda a sua nitidez.

\section{CIRCULAÇÃO, FLUXO}

É através da associação de cadeias de imagens e objetos que Eduardo Coimbra aponta a importância do que constitui a "circulação de energia" de uma instalação, tornando claro o aspecto de fluxo que aproxima matéria, vida e pensamento. Em Fatias de Memória / 1. Nascimento; 2. Formação do Corpo; 3. Movimento; 4. Repouso; 5. Morte (1995), instalação de grande impacto apresentada no Paço Im- 
perial (Rio de Janeiro), Coimbra justapõe os mais diversos elementos, considerados por ele enquanto objetos ou materiais em estado bruto: assim, somos confrontados com dois grandes montes de terra - sendo que um deles ergue-se a partir do lado exterior da galeria -, um tronco de madeira, duas bacias de metal, uma peça escultórica em madeira no formato de uma cama cortada pela metade, uma muleta construída em vidro e uma cadeira de rodas sem os pneus e o assento. Todos esses diferentes elementos são interligados por séries de linhas, materializadas através de barbantes ou tubos de plástico - por onde circula arde modo a construir uma extensa costura, a partir da qual os elementos individualizados perfazem um todo, ainda que fragmentário. Aí reside, a meu ver, o momento decisivo desta instalação: diante de coisas tão díspares, conduzidas à realização de pontuações físicas e literais, mas também alegóricas e metafóricas, como apreender uma possibilidade de sentido perceptivo que corresponda a tal deslizamento vertiginoso? Eduardo Coimbra coloca em funcionamento um jogo narrativo, construído a partir de cadeias de imagens, que equivale à instauração de um fluxo de energia próprio à invenção e produção de pensamento. Seria inviável conectar tantas situações heterogêneas - é o que o trabalho de Coimbra nos propõe - sem a construção de uma rede de interconexões e passagens como articulação de fluidez, a partir da qual o sentido emerge como derivado do processo mesmo de encadeamento de pensamento, sua multiplicação e espacialização.

\section{MEMÓRIA}

Carla Guagliardi vem conduzindo seu trabalho em torno de questões que envolvem tempo e memória, utilizando-se frequientemente de materiais de naturezas contrastantes, que se interagem. Na instalação Memória Líquida (1996, Galeria do IBEU, Rio de Janeiro), nos convida a uma experiência de disjunção entre dois espa- ços, um vivido multissensorialmente, mobilizando a totalidade do corpo, e outro visualmente, provocando apenas o olhar. Com a construção de um muro de tijolos, ocupando a área de entrada, Carla Guagliardi bloqueou efetivamente o acesso do público à sala de exposição, permitindo entretanto, por meio de alguns pequenos orifícios deixados em aberto no muro, que o espaço fosse acessado através da visão. Atrás dessa parede estavam colocados uma série de vasos de plantas, cada um deles conectado ao muro através de linhas de algodão, tensionadas em sentido descendente, do muro para as plantas. Incrustrados no muro, entre os tijolos, recipientes de vidro cheios de água, com diferentes tamanhos e formatos, recebiam a extremidade superior dos fios: assim, por meio de um efeito de capilaridade, a água contida nos recipientes de vidro era conduzida às plantas, junto ao chão da galeria. Ocorre que, ao obrigar o espectador a posicionar o olhar segundo os pequenos orifícios do muro, a artista limita e direciona a visão, construindo uma visibilidade parcial, fragmentária: a estratégia implica num controle parcial do corpo (Lygia Clark, em suas experiências sensoriais, muitas vezes procura bloquear um sentido para intensificar ou desreprimir outros), de modo a potencializar um olhar multiplicado nos inúmeros fragmentos de imagem pelo qual o visitante tenta compreender o espaço oferecido à contemplação. Este olhar, à medida que se multiplica, acaba por agir retroativamente, duplicado sobre si mesmo, acionando um jogo mnemônico movido pelo confronto entre diferentes formas de experimentação do espaço: a ação de lembrar é ativada aqui, tanto como associação de fragmentos dispersos no tempo e no espaço, quanto em termos de permanência, retenção, acumulação. As mesmas linhas que conduzem água para as plantas alimentam-se da energia do olhar, terminando por subjugá-lo, imobilizá-lo - mas apenas para libertá-lo mais adiante, já em velocidade de aceleração, através de um outro espaço, interfaceando, por dentro e por fora, o corpo do espectador. Memória Líquida con- 


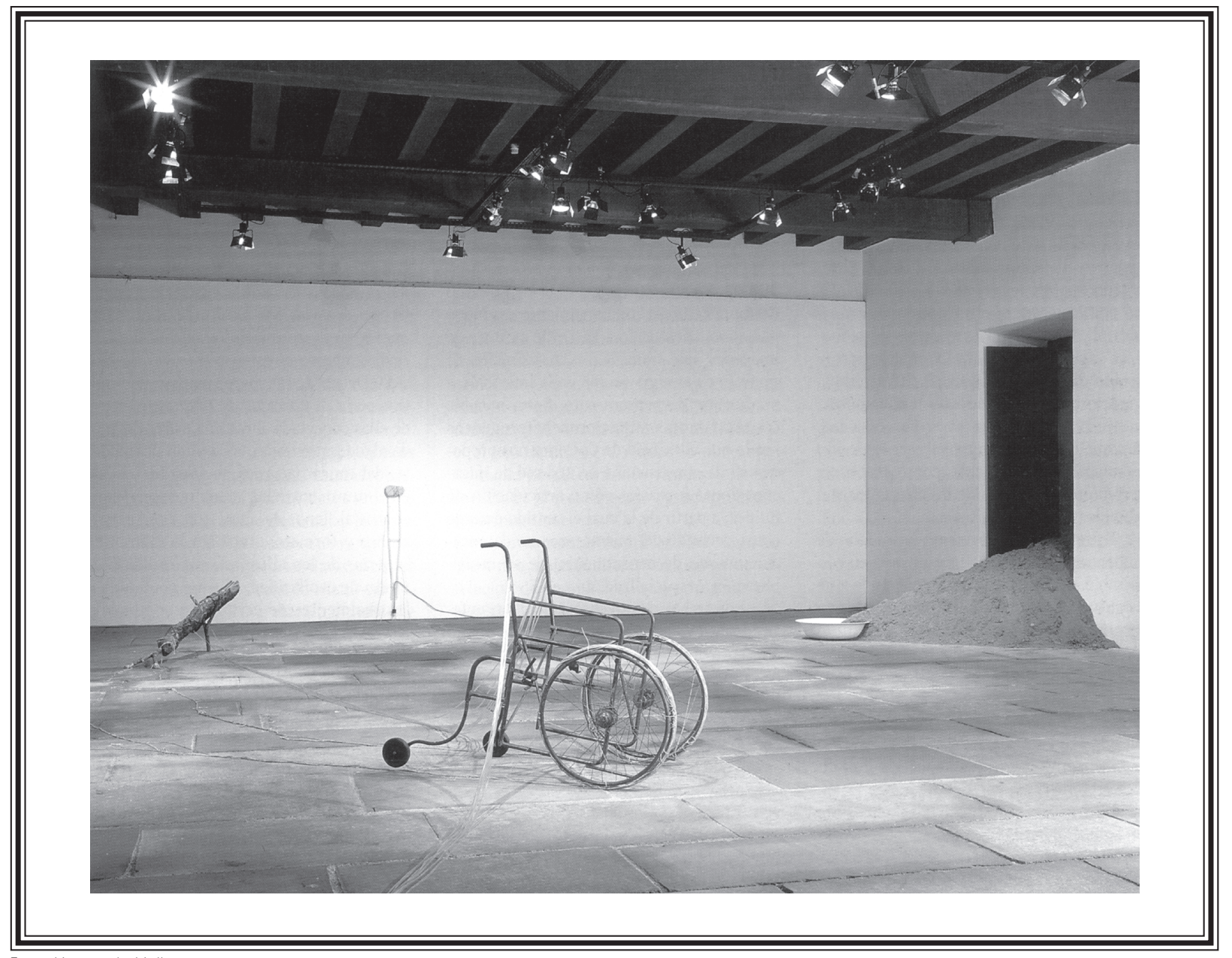

Fotos: Vicente de Mello

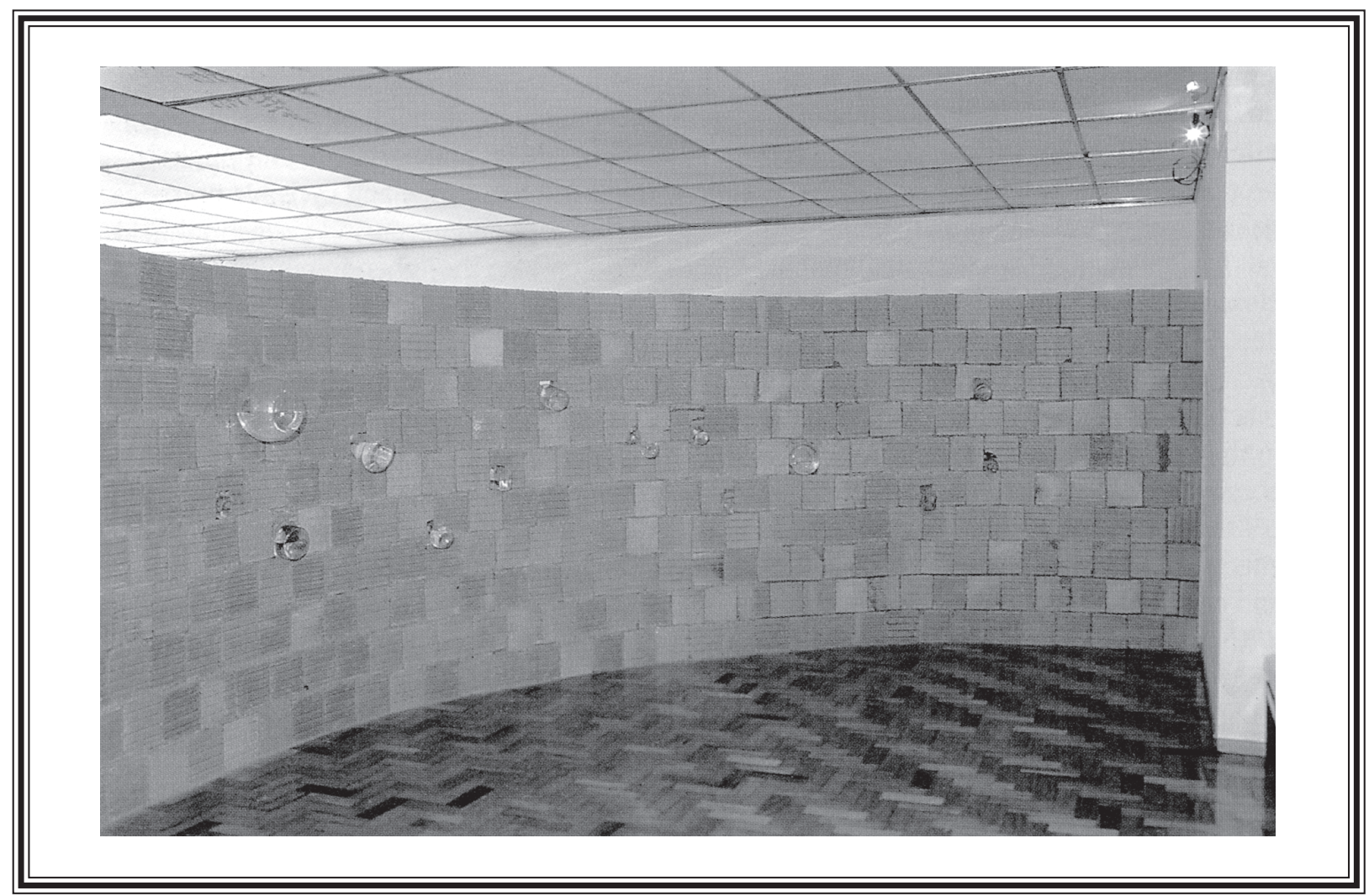


siste em uma operação de enfrentamento de duas formas fechadas de espacialidade - corpo vs. espaço bloqueado -, para desse modo obrigar ambos a uma violenta exteriorização, construindo entre eles passagens e fluxos transformadores.

\section{PROCESSO, ATUALIZAÇÃO}

A proposição Pássaros Migratórios (1992), de Sonia Labouriau, também procura trabalhar um conjunto de questões inter-relacionadas com experiência, processo, fluxo e memória. Misturando coloral (composto comestível que combina extrato de urucum e fubá) com cola de metil-celulose, a artista obtém uma massa moldável de cor vermelhoalaranjada, dotada de organicidade própria. Labouriau, então, elabora um procedimento para a produção de pequenos "pássaros", a partir de "quatro movimentos de mão", de modo a obter o resultado não a partir de determinações formais, mas em decorrência de um método operatório, processual: "procuro criar procedimentos que possam, como uma partitura, ser executados incorporando as circunstâncias" (8). Cada um dos pássaros assim produzidos é conservado dentro de um vidro convexo, protegido contra secagem e deterioração; ao mesmo tempo, um deles é escolhido e colocado dentro de um vidro côncavo, cheio d'água: agora, em um espaço de tempo de algumas horas até dois dias, o pássaro vermelho-alaranjado irá dissolver-se, “migrar para a água”, desfazendo sua transitória formalização, puro processo. É o próprio devir do objeto de arte que Pássaros Migratórios torna visível, ao assinalar um percurso de desmaterialização que reconduz qualquer cristalização em direção a um estado de fluxo, que inevitavelmente irá adquirir nova substância ao combinar-se com o fruidor/ experimentador, suporte de possível recepção e repotencialização contínua. Deixando traços de uma verdadeira memória líquida, cada estado de seu vôo pro- cessual indica etapas de uma constante metamorfose, a afirmar afinidades não só entre arte e transformação, como também entre arte e transmutação, pela interconexão de diferentes estados e pela facilidade em reformalizar-se nas condições mais diversas e adversas. Colocar em movimento o objeto de arte será refazê-lo novamente, escutar seu conjunto rítmico e deixar-se constituir por seu devir-experimentá-lo, experimentar-se.

\section{CONTAMINAC̦̃̃o, IRRADIAC̦ão}

Diante da experiência de adversidade, característica do ambiente brasileiro, e frente a um meio de arte de institucionalização precária, conduzi meu próprio trabalho plástico para preocupações com a articulação dos campos verbal e visual - e suas interfaces comunicativas -, desenvolvendo um projeto em torno da "materialidade" e "espacialidade do pensamento", caracterizando a obra em sua presença visível e invisível e propondo um campo sensorial também ocupado pela “fenomenologia do conceito". Desde 1989 desenvolvo o projeto NBP - Novas Bases para a Personalidade, a partir de objetos, desenhos, textos, instalações, diagramas, etc.: a preocupação é de estabelecer uma conexão direta com o espectador, transformando-o em veículo e suporte do jogo da arte, uma vez que sua presença aciona os maquinismos da obra, colocando-a em funcionamento. A proposta Você gostaria de participar de uma experiência ar tística?, por exemplo, iniciada em 1994, oferece ao participante um objeto para ser utilizado em sua casa, por um mês; o próprio participante registra suas ações, deixando-se (ou não) contaminar pelo projeto NBP - mas, de qualquer modo, envolvido em uma experiência de transformação, em que o objeto gradualmente se metamorfoseia, em função das atividades desenvolvidas. Trata-se de enfatizar conexões possíveis de serem estabelecidas entre corpo/indivíduo e objeto de
Na página

anterior,

Eduardo

Coimbra,

Fatias de

Memória,

1995.

Instalação com

diversos

materiais, Paço

Imperial, Rio

de Janeiro;

abaixo, Carla

Guagliardi,

Memória

Líquida, 1996.

Instalação com

diversos

materiais,

Galeria do

Ibeu, Rio de

Janeiro

Sonia S Labouriau, Colunata folder de exposição no Centro Cultural São Paulo, texto de Paulo Sérgio Duarte l"A Escul tura Impossivel"|, abril-maio/ 1997 


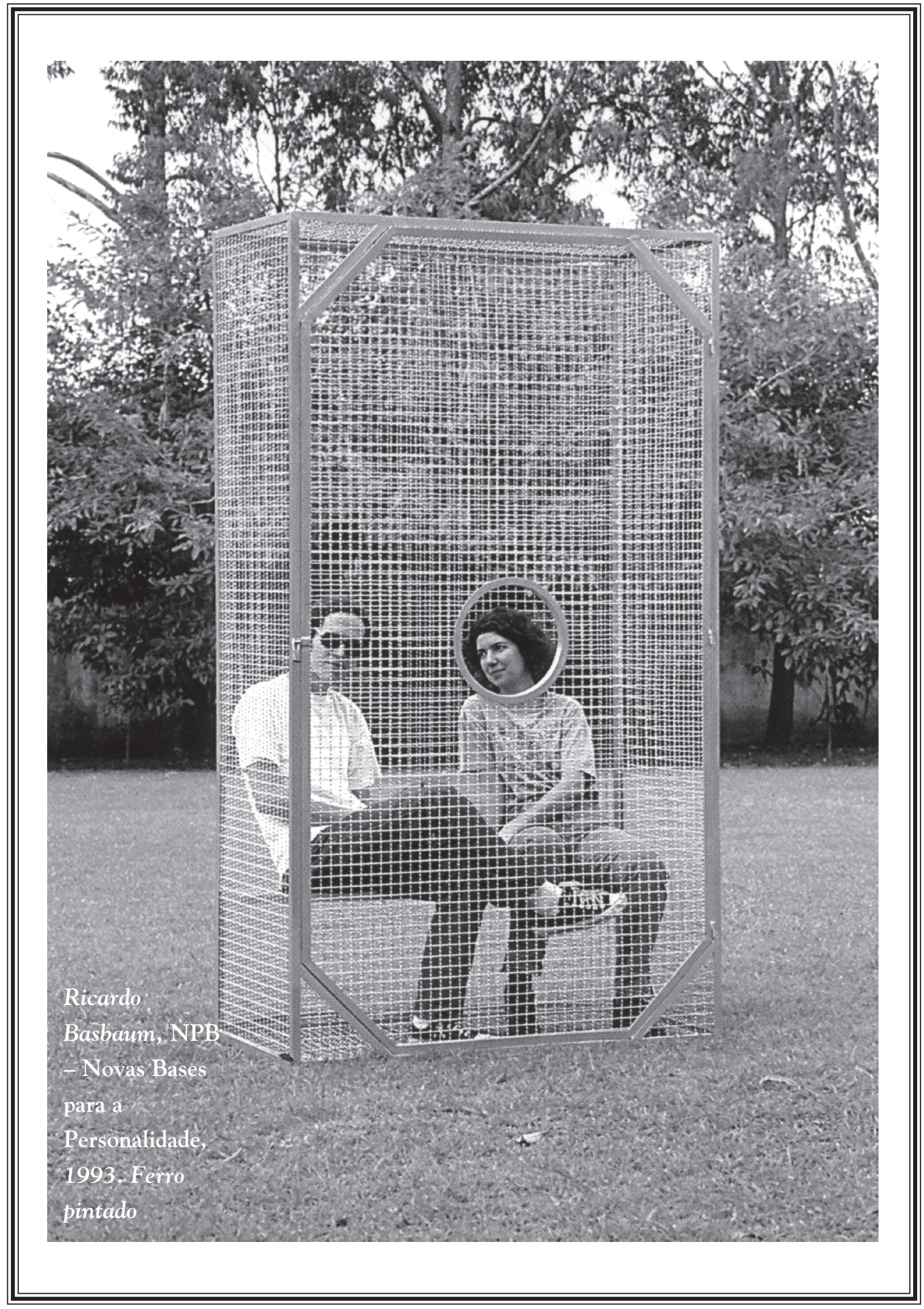




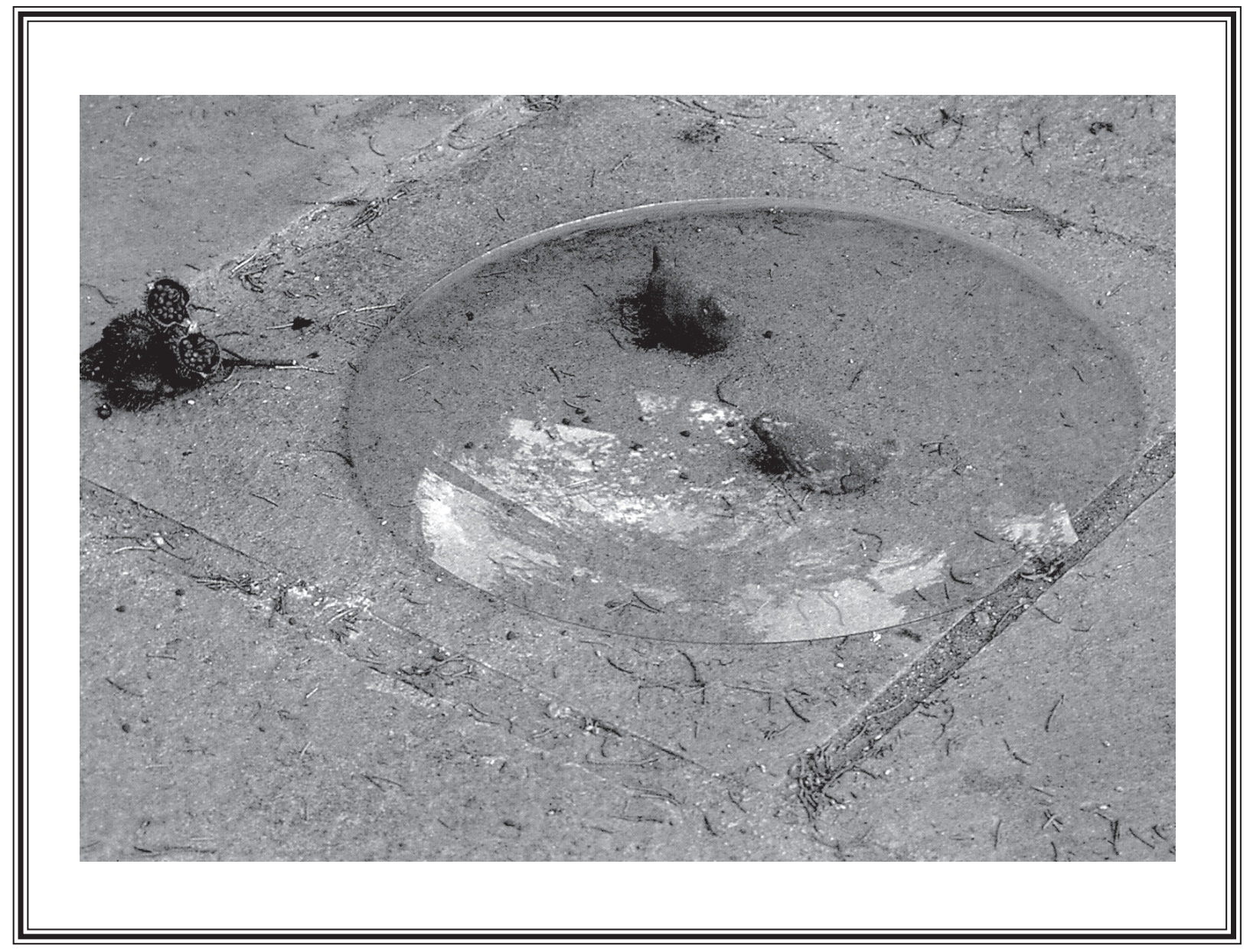

arte, produzindo ao mesmo tempo continuidades - no sentido de uma hibridização corpo/obra e descontinuidades - enquanto estranhamento de si e análise da experiência. Existe uma agressividade invasora que ambiciona, como João Modé ou Brígida Baltar, uma colonização do espaço da interioridade, mas a partir de uma estratégia compacta, em que o trabalho de arte é veículo para uma alteração quase genética - operação de implante, no espectador/participador (9), de um dispositivo gerador do fluxo artepensamento.

Os trabalhos aqui discutidos enfatizaram a exploração de uma espacialidade em estreito contato com as dimensões interiorizadoras - sejam receptivas ou projetivas. Mas o que particulariza esta produção é a exigência em não abandonar o confronto com um rico campo sensorial, assinalando a imprescindível importância da experiência. É necessário provocar e envolver o espectador em uma rede de estímulos múltiplos - de qualquer espécie - de modo a interferir em seu movimento perceptivo, e assim ocupar, colonizar aquele corpo que é também pura espacialidade em sua pulsão contínua dentro/fora: um corpo que é veículo, palco de combates, superfície projetiva. Diversas formas de condução do tempo foram apresentadas, indicando a força de aceleração própria de cada experimentação, em seu lançar-se sobre o outro - fruidor ativo, participante. $\mathrm{Na}$ rede de produção de pensamento, os trabalhos de arte constituem nós de rara potencialidade.

\section{Sonia \\ Labouriau, \\ Pássaros \\ Migratórios, \\ 1992. Coloral, água, vidro}

9 Tunga declarou certa vez que o melhor lugar para mostrar seus trabalhos seria no cérebro, entre os hemisférios direito e esquerdo. Melhor ainda se o indivíduo for disrítmico. 